\title{
Управление персоналом в государственных органах: социальные и психологические детерминанты
}

Щетинин А.А., Щетинина Д.П.

Проблематика кадровой работы является одним из наиболее актуальных направлений повышения эффективности деятельности любой организации, как коммерческой, так и государственной, причем во втором случае этим вопросам необходимо уделять повышенное внимание, учитывая особые условия труда государственных служащих, специфику мотивации их деятельности и выполняемых функций. В статье рассматриваются некоторые детерминанты управления персоналом в государственных органах. Раскрываются особенности управления персоналом на уровне отдела кадров, руководителя и сотрудников. Отмечается роль акмеологических и сочиально-психологических факторов в совершенствовании профессиональной подготовки госслужащих.

Ключевые слова: управление персоналом, госслужащие, сочиально-психологические характеристики.

Руководители коммерческих организаций давно оценили необходимость работы с кадрами, готовы оплачивать дорогостоящие семинары и тренинги по управлению персоналом. На сегодняшний день, почти во всех успешно развивающихся средних и крупных коммерческих компаниях есть подразделение или как минимум сотрудник, основа деятельности, которых заключается не в оформлении документов, сопровождающих прием новых сотрудников и их перемещение по должностям, а в создании такого климата в организации, чтобы работники могли и хотели решать те задачи, которые стоят перед ними. Эта тема затронута в работах многих, как отечественных, так и зарубежных авторов (Бадалов Л.М., Зюзин Д.И., Митчелл Г., Мошкова И.Н., Малов С.Л., Мощенко А.В., Сигов И.И., Шахова В.А. и др.).

Однако, вопросы, посвященные управлению служащими государственных органов, по-прежнему являются достоянием ведомственных совещаний и специализированных лекционных курсов. В различных отраслях государственной службы также создаются различные подразделения кадрового аппарата, отделы воспитательной работы, психологические службы и т.д., основной задачей которых является работа с персоналом, однако, зачастую их деятельность построена на устаревших принципах, заложенных советской бюрократической системой, а нормативная база их деятельности пронизана формализмом и демагогией, что 
в действительности проявляется в их неэффективности, когда реальная работа с государственным служащим заменяется написанием необходимых отчетов.

С одной стороны, это можно объяснить особенностями государственной службы, режимом секретности в отдельных её сферах, с другой - государственные служащие являются частью общества, которую невозможно рассматривать как обособленную категорию, соответственно, основные закономерности и принципы работы с кадрами в этой сфере схожи с другими организациями.

Итак, в любом государственном органе есть отдел кадров, однако, в силу организационно-технического, кадрового и финансового обеспечения набор функций отделов кадров достаточно ограничен, хотя по своей сути они призваны выстраивать целостную систему управления персоналом, включающую и обучение сотрудников, и оценку результатов их работы, и мероприятия, направленные на создание определенной корпоративной культуры организации и психологическое сопровождение деятельности как на уровне коллектива, так и отдельного государственного служащего. Мы не говорим уже о разработке и внедрении системы эффективного материального и нематериального стимулирования, реальном формировании кадрового резерва (когда на вышестоящую должность назначают действительно опытных, достойных сотрудников, независимо от их взаимоотношений с руководителем), работе с конфликтами в рамках поддержания оптимального социально-психологического климата в организации. Как и в советское время, способов воздействия на сотрудников предусмотрено немного - премии (причем суммы денежных поощрений зачастую выглядят смешно), поощрения нематериального характера (грамоты, благодарности) и, соответственно, замечания, выговоры, понижения в должностях и званиях и различные способы увольнения (эти методы, конечно, относятся не к стимулирующим, а к репрессивным).

Как правило, решение всех вышеизложенных проблем, помимо прочих, ложится на плечи руководителей структурных подразделений (департаментов, управлений, отделов). Поэтому, важно, чтобы руководитель понимал роль и назначение кадрового подразделения в управлении персоналом государственного органа, строил свою работу с его помощью и учетом рекомендаций. Таким образом, кадровые службы не должны быть лишь техническим придатком руководящих структур, занимаясь в основном организационно-оформительской работой, они должны активнее помогать руководству государственного органа в определении его кадровой политики, управлять служебным продвижением персонала, заниматься проблемами межличностных отношений, совершенствованием стиля деятельности сотрудников и многими другими вопросами.

Комплексный анализ объективных организационно-функциональных и социально-психологических условий деятельности сотрудников государственных учреждений и органов, в том числе и силовых структур, свидетельствует, что государственная служба является одним из наиболее «деформирующих», «маргинализирующих» и психотравмирующих личность видов профессиональной деятельности. Поскольку в условиях государственной службы на человека воздействуют 
не только функционально-профессиональные факторы, но и организационная регламентация деятельности, а в случае с правоохранительными органами - в наивысшей степени «агрессивность» профессиональной среды [5].

Все это требует повышения эмоционально-волевой и мотивационной составляющих деятельности, а также сформированности психологической готовности людей, с одной стороны, противостоять и, с другой стороны, адаптироваться к этим довлеющим факторам за счет формирования эмоционально-волевой устойчивости каждого сотрудника на основе учета и развития их личностных качеств.

Напряженная организационная, интеллектуальная и эмоциональная обстановка, постоянно сопровождающая деятельность государственных служащих, приводит к случаям нервно-психических срывов и нервных расстройств. Необходимость своевременного выявления и профилактики подобных фактов возможна только в условиях постоянного психодиагностического контроля, особенно тех сотрудников, которые выполняют свои функциональные обязанности в сложных, экстремальных условиях (военнослужащие, сотрудники правоохранительных структур и др.).

Кроме этого, рамки должностных обязанностей ограничивают свободу развития в профессиональном и личном плане, что может привести к переходу грамотного, подготовленного специалиста в иные сферы деятельности, что часто и происходит с достигшими определенного уровня государственными служащими. Именно поэтому в ряде случаев государственную службу многие оценивают лишь как хороший трамплин для дальнейшей карьеры, что для государственной службы является крайне неэффективной моделью развития.

Коренная структурная реорганизация органов управления персоналом государственной службы, изменение и дополнение их функционального назначения стали в настоящее время задачами первостепенной важности, требующими законодательного, научного, методического и организационного решения. Важнейшие компоненты системы управления персоналом государственной службы формируются в соответствии с уровнями системы управления государственной службой Российской Федерации. Она создается на федеральном уровне, на уровне субъекта Российской Федерации и на уровне государственного органа. Ключевым звеном этой системы является кадровая служба государственного органа.

До тех пор, пока кадровая политика государственной службы не будет подвергнута реальным, а не формальным изменениям, не будет налажена достаточная организационная и методическая помощь отделам кадров со стороны Администрации Президента РФ и Правительства РФ, большое значение для кадровой работы будет иметь то, какие люди управляют и работают в каждом конкретном подразделении в организациях государственной службы.

В связи с этим на первый план выходит подготовка и переподготовка кадров государственной службы с необходимыми для продуктивной управленческой деятельности психологическими характеристиками, позволяющими эффективно осуществлять поставленные перед ними задачи. Ошибка в ориентации кадров госслужбы лишь на получение экономических и юридических знаний заключается 
в том, что в условиях России лишь этих знаний недостаточно. Важной стороной управленческих процессов выступают психологические знания, роль которых практически не учитывается. Игнорируются особенности психического состояния общества, поражения значительных слоев населения психическими болезнями, не учитываются региональные особенности развития: традиции, нравы, мнения людей, их социальное самочувствие. Это, на наш взгляд, является одним из существенных факторов, влияющих на государственно-правовое и общественное развитие России.

К кадрам государственного управления должны предъявляться определенные требования в личностном и профессиональном планах: самосознание, социальная направленность и постоянная включенность в процесс самооценки и принятия решения, мотивация достижения и другие внутренние детерминанты, обусловливающие продуктивную реализацию творческого потенциала человека.

Особое внимание при отборе кандидатов на государственные должности следует уделять социальным особенностям, которые обеспечивают успешное взаимодействие их с командой, а также с населением и каждым человеком. Изучение и учет акмеологических и социально-психологических факторов является важным резервом совершенствования профессиональной подготовки госслужащих.

В научных публикациях, да и на бытовом уровне утвердилось мнение, что государственные служащие это особая категория людей, характеризующихся определенными психологическими особенностями личности, что задачи, которые выдвигаются перед ними, они должны осознавать еще до уровня профессиональной подготовки, так как именно в это время закладывается восприятие этических ценностей, занимающих в служении государству и обществу первостепенное значение и относящихся к группе общегражданских принципов. Соответствующие исследования были проведены кафедрой акмеологии и психологии профессиональной деятельности Российской академии государственной службы при Президенте РФ в общеобразовательных учреждениях [2]. Результатом эксперимента стали данные о том, что в становлении государственного служащего как субъекта профессиональной деятельности первостепенное значение имеют психические образования, входящие в базис личности, обеспечивающие целостность и устойчивость ее структуры, придающие социальную значимость профессиональным установкам. К числу таких образований относится Я-концепция госслужащего. Поэтому на этапе допрофессиональной подготовки важно опираться на особенности развития Я-концепции той личности, которая предполагает в будущем профессиональную деятельность в системе государственной службы [5].

Конечно, речь не идет о выделении «касты государственных служащих», или тем более категории непригодных к государственной службе, что противоречило бы ст. 32 Конституции РФ, закрепившей равный доступ к государственной службе для всех российских граждан.

Но все же важным аспектом в системе психологической подготовки государственных служащих является выявление профессиональной пригодности или 
непригодности специалиста, претендующего на должность и установление квалификационных требований для их замещения. С правовой точки зрения установление такого рода критериев является затруднительным. Например, Закон «О милиции» указывает, что сотрудником милиции может быть гражданин, способный по своим личным и деловым качествам исполнять должностные обязанности. Данная формулировка достаточно общая, что затрудняет её практическое применение. Решением проблемы могло бы стать закрепление на законодательном уровне обязанности прохождения унифицированных психологических тестов, что на данный момент регулируется ведомственными актами. Крайне важным является учитывать человеческий фактор, насколько специалист верен идеалам профессии и компетентен с точки зрения профессиональных знаний.

Исходным компонентом управленческой деятельности руководителя является умение ставить цели и вовлекать работников в их реализацию. Трудность этого заключается в том, что цели государственных органов не всегда совпадают с жизненными целевыми ориентирами индивидов.

В настоящий момент в РФ намечается положительная тенденция, свидетельствующая о том, что специалист имеет возможность сделать карьеру на государственной службе, приложив определенные усилия, постоянно развиваясь и совершенствуясь и следуя профессиональным и этическим принципам госслужбы. Но консервативные установления советского периода, связанные с карьерным ростом только по решению вышестоящих инстанций создают серьезные психологические проблемы современным государственным служащим. Так, по данным ученых Российской академии государственной службы при Президенте Российской Федерации одним из наиболее важных и существенных факторов продуктивной деятельности государственных служащих является их успешная карьера. В настоящее время государственные служащие в подавляющем большинстве неуверенны в возможности своего служебного продвижения за счет трудолюбия и развития профессиональных качеств, что создает психологические препятствия для эффективной работы и профессионального развития. Кроме того, удовлетворенность госслужащих своим социальным и служебным положением эксперты определяют в пределах 10-13\%. Если в организации создана и функционирует отлаженная система планирования и развития карьеры, то она не только обеспечивает достижение корпоративных целей, но и одновременно поддерживает устойчивость сотрудников, способствует формированию деловой оптимальной атмосферы [7].

Психологические особенности подготовки государственных служащих в РФ, обусловлены сложным характером и особенностями государственного устройства страны, находящейся в стадии реформирования. Пока что не создано объективных предпосылок уверенности государственных служащих в своем будущем и специально созданных условий для достижения ими благополучия. Внутреннее (личностное) и внешнее (достойное материальное положение) благополучие способно сформировать у государственного служащего положительный образ выбранной профессии и этические принципы, являющиеся основой 
общегражданской группы принципов его работы и в итоге послужить прочной основой эффективного выполнения им своих должностных обязанностей в строгом соответствии с законом.

В ситуации повышения социальной ответственности и инициативности государственной службы в России особую значимость приобретает разработка способов и форм эффективного управления деятельностью и поведением служащих.

На данный момент социологические исследования показывают, что пока что основными мотивами поступления людей на государственную службу являются личные факторы - гарантия постоянной работы, стабильности положения, стремление реализовать свои профессиональные качества и повысить свое материальное благополучие, желание иметь широкие связи с людьми, которые могут быть полезны в жизни, стремление занять престижное место в обществе [6]. Социально значимые мотивы профессиональной деятельности (желание принести пользу обществу и государству) не столь важны для служащих.

Реформирование системы государственной службы Российской Федерации, и в первую очередь системы управления кадровым потенциалом, должно быть направлено на переориентацию целевой организации поведения служащих.

В данном направлении достаточно эффективным представляется применение социокультурной модели управления персоналом [4]. Управление посредством организационной культуры позволяет использовать возможности и преимущества социокультурных факторов. Концептуальное определение миссии государственной службы (главной целевой функции), повышение культуры профессиональной деятельности работников, использование самоорганизационных технологий: традиций и ритуалов, межличностных коммуникаций, способны воздействовать на организационное поведение, закрепить наиболее «желательные» для организации государственных служащих стандарты деятельности. Социокультурный контекст поведения опирается на косвенные методы воздействия, использует ресурсы, способности и творческий потенциал каждого работника. В данном случае основой управления персоналом становятся не внешние, жесткие детерминанты в виде направляющих управленческих воздействий, а организационная культура как комплекс институциональных и нравственных норм и регуляторов, которая приобретает определяющее значение для профессиональной деятельности и организационного поведения в государственной службе. Культурные мотивации поведения отличаются большей осознанностью, не жесткостью стиля деятельности. Они учитывают личностные и групповые особенности, основываются на социальных нормах, принятых и разделяемых большинством членов организации и потому более эффективных.

Еще одним малоэффективным аспектом современного управления персоналом государственных органов является технология оценки эффективности деятельности. Приемы и методы оценки результативности и эффективности служебной деятельности имеют конечной целью поддержание позитивной мотивации работников к труду [3]. В государственных органах зачастую реальные достижения и результаты 
деятельности служащих оцениваются ниже, чем не связанные с реальностью надуманные и фальсифицированные отчеты и показатели статистики, что в конечном итоге заставляет прибегать к нарушениям закона с целью формирования видимости положительной динамики работы органа или подразделения.

Цели любой деятельности должны определяться, исходя из сформулированных стратегических видений - миссии деятельности, а также с учетом технологического и ресурсного обеспечения.

Обобщая все вышесказанное можно выделить несколько целей, реализация которых позволит существенно повысить эффективность кадровой работы в государственных органах и повысить уровень профессионализма служащих.

Во-первых, в системе государственного аппарата должна быть создана конкурентная среда с привлечением современных технологий и высокой инновационности управления, причем возможно привлечение коммерческих организаций, способных взять на себя выполнение некоторых функций. Для этого необходимо обеспечить открытость конкурса при приеме на государственную службу, достигаемую широким информированием о проходящих наборах, прозрачностью процедуры приема на службу, созданием сети кадровых служб государственных органов, ориентированных на раннее информирование молодежи о возможностях карьеры на государственной службе, отбор талантливой молодежи и включения ее в специализированные учебные программы, что будет стимулировать действующих государственных служащих к повышению своего профессионализма.

Первая цель может быть эффективной только на фоне повышения престижности государственной службы, формирования в обществе мотивации поступления на государственную службу. Это предполагает повышение общественного статуса государственного служащего, возможность получения образования, которое должно даваться только уже принятым на государственную службу, достойное материальное вознаграждение, стабильность общественного положения, включающего специальную систему реальных социальных гарантий, применение иных способов стимулирования (система государственных наград, использование системы кредитов, ссуд и т.д.).

Во-вторых, необходимо обеспечить тесную двустороннюю связь с гражданским обществом, предполагающую глубокую включенность органов государственной власти и широких масс граждан в формирование нормативных актов, регламентирующих деятельность госслужбы, открытость и подконтрольность процесса государственного управления общественным институтам, введения обязательности внешнего отзыва при оценке индивидуальной деятельности госслужащих, а также реально действующей системы информирования руководителей о деятельности подчиненных с помощью обращений, жалоб граждан, «горячих линий» и «телефонов доверия».

В заключение важно подчеркнуть, что поставленные цели и принципы управления персоналом в органах государственной службы требуют координации работы, как на федеральном уровне, на уровне субъектов Российской Федерации, а также и на уровне конкретного государственного органа. 


\section{Литература}

1. Базаров Т.Ю., Беков Х.А., Аксенова Е.А. Методы оценки управленческого персонала государственных и коммерческих структур. - М., ИПК Госслужбы, 1996.

2. Деркач А.А. Акмеологические стратегии развития. - М.: Изд-во РАГС, 2006.

3. Иванцевич Дж., Лобанов А.А. Человеческие ресурсы управления. - М.: Дело, 2002.

4. Карташева Л.В., Никонова Т.В., Соломанидина Т.О. Организационное поведение - М.: ИНФРА-М, 2007.

5. Носс И.Н. Акмеологическая диагностика государственных служащих / под ред. А.А. Деркача. - М.: Изд-во МГОУ, 2007.

6. Психологические аспекты подбора и управления персоналом: библиотека журнала «Управление персоналом» - М., 2006.

7. Психология управления / отв. ред. Удальцова М.В.- М.: ИНФРА-М; Новосибирск: «Сибирское соглашение», 2006. 